Article

\title{
The Effect of Spiritual Care on Depression in Patients Following Coronary Artery Bypass Surgery: A Randomized Controlled Trial
}

\author{
Fereshteh Tajbakhsh ${ }^{1}$, MohammadAli Hosseini ${ }^{1, *}$, Masoud Fallahi-Khoshknab ${ }^{1}$ (D), \\ Asghar Rokofian ${ }^{2}$, Mehdi Rahgozar ${ }^{3}$ and Patricia Mary Davidson ${ }^{4}$ \\ 1 Nursing Department, University of Social Welfare and Rehabilitation Sciences, Tehran, Iran; \\ frtajbakhsh@yahoo.com or frtajbakhsh@yahoo.com (F.T.); fallahi@uswr.ac.ir (M.F.K.) \\ 2 Department of Religious Education, University of Social Welfare and Rehabilitation Sciences, Tehran, Iran; \\ aliali1358@gmail.com \\ 3 Statistic Department, University of Social Welfare and Rehabilitation Sciences, Tehran, Iran; \\ ma.rahgozar@uswr.ac.ir \\ 4 Nursing School, Johns Hopkins University, Baltimore, MD 21218, USA; pdavidson@jhu.edu \\ * Correspondence: mahmaimy2020@gmail.com or mo.hoseini@uswr.ac.ir; Tel.: +982-122-180-132
}

Received: 31 January 2018; Accepted: 3 May 2018; Published: 14 May 2018

\begin{abstract}
The aim of this study was to determine the effect of a nurse-delivered spiritual care intervention on depression following coronary artery bypass graft (CABG) surgery. A semi-experimental study was performed in Baqiyatallah al-Azam Military Hospital of Tehran, Iran in 2013. Sixty-eight patients undergoing coronary artery grafts were purposefully selected and randomly assigned into the intervention $(n=34)$ and control (usual care) groups $(n=34)$. The intervention group received five sessions of spiritual care lasting between 45-60 minutes using the approach of Bergin Richards (2005). The control group received only routine standard care. The mean depression scores were measured using the depression subscale of the Depression Anxiety Stress Scale (DASS-21). At baseline $(p=0.051)$, there were no differences in the mean depression scores. Post intervention, statistically significant differences were observed in the mean depression scores between groups $(p<0.001)$. The results showed that the use of spiritual care can decrease depression in the intervention group. These findings suggested that nurses could use spiritual care to improve psychological care.
\end{abstract}

Keywords: depression; spirituality; coronary artery bypass graft

\section{Introduction}

Coronary artery bypass surgery is among the most common surgical procedures performed in the United States of America, amounting to more than 515,000 per year. (Gallagher and McKinley 2009) Although this procedure markedly improves morbidity and mortality (Eisenberg et al. 2005), many patients experience psychological distress postoperatively (Duits et al. 2002). Depression and coronary artery disease are highly comorbid conditions with estimates of comorbidity from $14 \%$ to $47 \%$ (Simha Ravven et al. 2013). Almost one in every five patients experience major depressive symptoms or at least a mild form of depression according to the DSM-IV criteria, periodically during recovery after open-heart surgery (Freedland et al. 2009). Postoperative depression impaired physical-mental recovery; it also delayed wound healing and wound infection (Doering et al. 2005), and adverse cardiovascular events challenged recovery (Rafanelli et al. 2006). Depressive symptoms reduce the individual's capacity to control their diet, engage in physical activity, visit a doctor regularly, and adhere to other standards of treatment (Vural et al. 2008). Many studies have shown that depression increases the risk of myocardial infarction, has a negative impact on participation in rehabilitation programs 
(Stafford et al. 2007), increases morbidity, mortality, and hospital admissions (Holzapfel et al. 2009; Carney and Freedland 2008), decreases the efficacy of self-care behaviors, and raises health care costs and burden (Rutledge et al. 2009).

The World Health Organization stated that health has four dimensions: physical, mental, social, and spiritual. Addressing each of these dimensions is an important consideration for nurses, and it helps patients cope and adjust to illness and find meaning in their life (Karimollahi et al. 2008). Nurses should be committed to the concept of holistic care and pay attention to the physical, psychological, emotional, social, and spiritual aspects of patients' care needs (Adib-Hajbaghery and Saeadnejad 2016). One component of a healthy life is paying attention to the individual's spiritual needs (azhdarifard, ghazi, and nouranipour 2010). Spiritual care is defined as "actions to meet the spiritual needs of the patient and family" (Melhem et al. 2016). Spiritual care has negative correlations with stress, anxiety, depression, aggression, and obsession in both patients and caregivers (Hosseini et al. 2013). Spiritual care is an important consideration for nursing care (Ross 2006). Nurses provide spiritual care to meet the spiritual needs of the patients and their family, in an attempt to improve the quality of life during the course of the patient's disease (Melhem et al. 2016). Between 1984-2005, studies on spiritual therapy showed positive benefits in persons with mental health problems such as eating disorders, stress, anxiety, and depression (Smith et al. 2007). Whelan-Gales et al. (2009) investigated the relationship between spiritual health and spiritual care with depressive symptoms among 24 patients with acute heart failure, and demonstrated an inverse relationship between spiritual care and depression (Whelan-Gales et al. 2009). In their study, Braxton et al. (2007) evaluated the relationship between spirituality and depression, and determined that spirituality improved mental health (Braxton et al. 2007). Koenig (2007) showed that frequent religious activities such as worship, prayer, Bible reading, and a high intrinsic religiosity improved the remission of depression (Koenig 2007). In a study conducted in the United Kingdom by McCoubrie and Davies, it was observed that there was an inverse correlation between spirituality and anxiety and depression (McCoubrie and Davies 2006). Oxman et al. found that a lack of religious belief is a risk factor for postoperative mortality in cardiac patients (Oxman et al. 1995). As a coping strategy, religion can have a positive effect in helping individuals cope (Rippentrop et al. 2005).

In an integrative review article in Iran, Hosseini et al. (2013) reported that spirituality plays an important role in the way people live and die. The majority of studies on spiritual and religious interventions in Iran's health care system have focused on patients' needs toward spiritual care and health professionals' spiritual approaches, as well as factors that influence their spirituality. In addition, this review demonstrated the positive correlation among spiritual care and hope, well-being, quality of life, coping, job satisfaction, happiness, and mental health. Moreover, there was a negative correlation between spiritual care and depression, anxiety, stress, aggression, and obsession (Hosseini et al. 2013).

Hosseini's study indicated a positive impact of spiritual care on reducing anxiety and depression, coping with illness, and enhancing hope (Hosseini et al. 2013). To the best of the authors' knowledge, there are limited data on the impact of spiritual care on depression in patients undergoing coronary artery bypass graft (CABG). The aim of this study was to examine the effect of spiritual care on patients' depression after coronary bypass surgery, using a culturally appropriate intervention.

\section{Methods}

\subsection{Design}

A randomized controlled trial was conducted to compare two groups: intervention and control before and after spiritual care. This study was performed from September 2013 to March 2014 in the Baqiyatallah hospital rehabilitation center in Tehran, Iran. The study population consisted of patients who participated in a cardiac rehabilitation program following CABG surgery. Based on prior studies, with $97 \%$ confidence level, a test power $(1-\beta)$ of 0.9 , the mean difference $(d)$ of 6.5 , and an anxiety variance of $s_{2}=11.7$, data were calculated for 68 persons: $(n 1=n 2=\{2[Z(1-a / 2)+Z(1$ 
- $\beta$ ) $] 2$ s2\}/d2). (Hosseini et al. 2013) Participants scheduled for coronary artery bypass graft were recruited considering the following inclusion criteria: (a) ability to communicate with the researcher effectively during the initial interview; (b) willingness to participate in the research; (c) ability to handle meetings and spiritual interventions; (d) physical and mental fitness to answer the questions; (e) sufficient reading and writing ability; (f) ability to speak Persian language; and (g) either Muslim and Shia. The following patients were excluded: (a) inability to participate in cardiac rehabilitation; and (b) patients who had severe depression or a history of other psychological disorders (based on the last medical records). A statistician generated a randomly assigned schedule. All 68 patients were selected based on the inclusion criteria, and were then randomly assigned to intervention $(n=34)$ and control $(n=34)$ groups by simple random sampling, based on a table of random numbers (Figure 1$)$. After obtaining consent for inclusion, participants in the intervention groups, in addition to the routine care, received spiritual care based on Richards and Bergin's model, which focuses on the Islamic religion for five sessions by a researcher under the supervision of a clergy. Each session lasted for between 45 minutes and one hour. The following spiritual-religious strategies were proposed: (1) reading a sacred religious book (The Holy Quran); (2) prayer; (3) expression of a religious patterns story; (4) participating in religious-spiritual programs; (5) repentance and forgiveness; and (6) intellectual analysis of ethical values. The control group only received routine nursing care, which included physical care and emotional reassurance as part of the postoperative routine care. Participants and outcome assessors were aware of the treatment assignments. Consequently, upon the instruction of the ethics committee after testing, researchers presented some spiritual care for patients in the control group (after surgery), and a condensed version of the intervention was provided post intervention, including the provision of a $\mathrm{CD}$ containing all of the education materials.

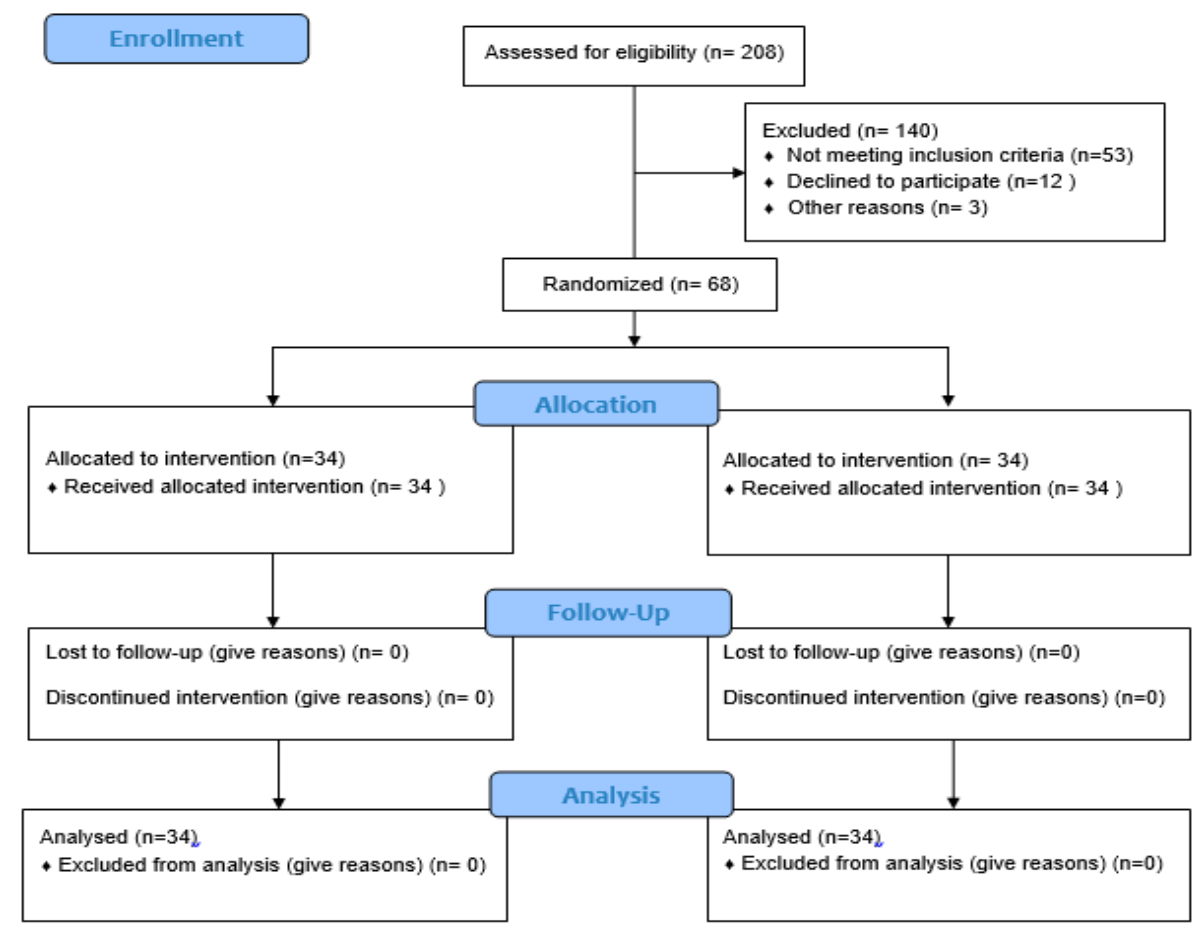

Figure 1. Consort flow chart.

\subsection{Instrument and Data Analysis}

The researchers used the demographic information inventory, which was aimed at collecting the patients' demographic characteristics (age, gender, marital status, employment, education, history of hospitalization, history of mental illness, surgery, previous teaching experience about spiritual care), and Depression Anxiety Stress Scale (DASS-21) for measuring patients' depression levels. The DASS 
consists of 21 items in three subscales: seven for anxiety, seven for depression, and seven for stress; it is ranked as: Normal $=0-9$, Mild $=10-13$, Moderate $=14-20$, Severe $=21-27$, Extremely Severe $=$ $28+$. The minimum score of any questions is zero, and the maximum score is three. Several studies conducted in Iran have confirmed the validity of this Persian type of DASS tool. Hanifi et al. confirmed the reliability of this tool: anxiety Cronbach's alpha $=0.95$, stress alpha $=0.89$, and depression alpha $=0.99$ (Hanifi et al. 2012), based on the total sample. Jamshidi et al.'s study demonstrated the overall reliability of the questionnaire, with a Cronbach's alpha coefficient of 93\% (Jamshidi et al. 2012). In another study, the reliability of this scale in a sample population of 400 people was reported as follows: depression (0.70), anxiety (0.66), and stress (0.76) (Sahebi et al. 2005). For data analysis, SPSS software version 20, and the Chi-square test was used to check the consistency of demographic groups with regard to spiritual care, and an independent t-test was used to compare the mean of the depression subscale score before and after spiritual care between the intervention and control groups. Prior to their participation in the study, the patients completed the informed consent form. Research permission was obtained from the ethical committee of the University of Social Welfare and Rehabilitation Sciences (30 March 2013-No, 92/801/2/8400). In addition, studies were approved by the Iranian Registry of Clinical Trials (2014; Registration ID: IRCT2014112420072N1).

\section{Results}

As illustrated in Table 1, participants' demographic conditions showed that both groups were matched before the study. Overall, $55 \%$ of participants had a one-time hospitalization history, and $32 \%$ had a history of one-time surgery.

Table 1. Distribution of demographic variables of participants.

\begin{tabular}{|c|c|c|c|c|c|c|}
\hline \multirow{2}{*}{$p$-Value } & \multicolumn{2}{|c|}{ Intervention } & \multicolumn{2}{|c|}{ Control } & \multirow{2}{*}{ Groups } & \multirow{2}{*}{ Variables } \\
\hline & $\%$ & Count & $\%$ & Count & & \\
\hline \multirow[t]{2}{*}{$0 / 307$} & $48 / 4$ & 15 & $61 / 3$ & 19 & Male & \multirow{2}{*}{ Gender } \\
\hline & $51 / 6$ & 16 & $38 / 7$ & 12 & Female & \\
\hline \multirow{4}{*}{$0 / 233$} & $6 / 5$ & 2 & $12 / 9$ & 4 & Illiterate & \multirow{4}{*}{ Education } \\
\hline & $35 / 5$ & 11 & $32 / 3$ & 10 & Elementary & \\
\hline & $22 / 6$ & 7 & $38 / 7$ & 12 & Junior high school & \\
\hline & $35 / 5$ & 11 & $16 / 1$ & 5 & High school & \\
\hline \multirow[b]{2}{*}{ 0/130 } & $93 / 5$ & 29 & $80 / 6$ & 25 & Parents & \multirow{2}{*}{ Tutelage } \\
\hline & $6 / 5$ & 2 & $19 / 4$ & 6 & Care center & \\
\hline \multirow{4}{*}{$0 / 851$} & $41 / 9$ & 13 & $45 / 2$ & 14 & ALL * & \multirow{4}{*}{ Cancer type } \\
\hline & $16 / 1$ & 5 & $19 / 4$ & 6 & CLL * & \\
\hline & 29 & 9 & 29 & 9 & $\mathrm{AML}^{*}$ & \\
\hline & $12 / 9$ & 4 & $6 / 5$ & 2 & $\mathrm{CML}^{*}$ & \\
\hline \multirow[b]{2}{*}{$1 / 000$} & $9 / 7$ & 3 & $12 / 9$ & 4 & Yes & \multirow{2}{*}{$\begin{array}{c}\text { History of psychological } \\
\text { disorders }\end{array}$} \\
\hline & $90 / 3$ & 28 & $87 / 1$ & 27 & No & \\
\hline $0 / 508$ & \multicolumn{2}{|c|}{$14 / 5 /(2 / 02)$} & \multicolumn{2}{|c|}{$15(2 / 86)$} & \multicolumn{2}{|c|}{ Age } \\
\hline $0 / 871$ & \multicolumn{2}{|c|}{$28(12)$} & \multicolumn{2}{|c|}{$30(16)$} & \multicolumn{2}{|c|}{ Hospitalization period (days) } \\
\hline $0 / 622$ & \multicolumn{2}{|c|}{$5 / 9(3 / 65)$} & \multicolumn{2}{|c|}{$6 / 38(4 / 03)$} & \multicolumn{2}{|c|}{ Number of chemotherapies } \\
\hline
\end{tabular}

* Acute lymphocytic leukemia (ALL) * Acute myeloid leukemia (AML) * Chronic myeloid leukemia (CML) * Chronic lymphocytic leukemia (CLL).

There was no significant difference between the two groups before the study, and both groups were matched.

Table 2 shows that there was a significant within-group difference regarding the mean scores for depression and pain before and after intervention in each group $(p<0.05)$. The present study focused on depression; there was no significance between-group differences before the study, and both groups were matched in depression scores. 
Table 2. Comparison of pain and depression in pre-test between intervention and control groups.

\begin{tabular}{|c|c|c|c|c|c|}
\hline$p$-Value & $\mathbf{t}$ & SD & Mean & Gr & \\
\hline \multirow{2}{*}{$0 / 606$} & \multirow{2}{*}{$-0 / 519$} & $13 / 99$ & $58 / 93$ & Intervention & \multirow{2}{*}{ Pain } \\
\hline & & $7 / 59$ & $57 / 45$ & Control & \\
\hline \multirow{2}{*}{$0 / 331$} & \multirow{2}{*}{$-0 / 980$} & $6 / 89$ & $36 / 16$ & Intervention & \multirow{2}{*}{ Depression } \\
\hline & & $10 / 16$ & $34 / 00$ & control & \\
\hline
\end{tabular}

At baseline, there were no significant differences. Table 3 presents, according to the probability value obtained based on the independent $t$-test, that there were no between-group differences in mean depression scores in the intervention and control groups before intervention. Whereas, after intervention, there were significant between-group differences $(p<0.001)$.

Table 3. Comparison of pain and depression in post-test between intervention and control groups.

\begin{tabular}{|c|c|c|c|c|c|}
\hline $\mathbf{P} * *$ & $\mathbf{P} *$ & Mean \pm SD & & Group & \\
\hline \multirow{4}{*}{$0 / 001$} & \multirow{2}{*}{$<0 / 001$} & $58 / 9 \pm 13 / 99$ & Before & \multirow{2}{*}{ Intervention } & \multirow{4}{*}{ Pain } \\
\hline & & $32 / 7 \pm 6 / 58$ & After & & \\
\hline & \multirow{2}{*}{$0 / 126$} & $57 / 4 \pm 4 / 59$ & Before & \multirow{2}{*}{ Control } & \\
\hline & & $53 / 29 \pm 13 / 25$ & After & & \\
\hline \multirow{4}{*}{$<0 / 001$} & \multirow{2}{*}{$<0 / 001$} & $34 / 10 \pm 0 / 16$ & Before & \multirow{2}{*}{ Intervention } & \multirow{4}{*}{ Depression } \\
\hline & & $30 / 09 \pm 10 / 46$ & After & & \\
\hline & \multirow{2}{*}{$0 / 221$} & $36 / 16 \pm 6 / 89$ & Before & \multirow{2}{*}{ Control } & \\
\hline & & $18 / 19 \pm 9 / 31$ & After & & \\
\hline
\end{tabular}

Table 3 shows that according to the probability value obtained by a paired $t$-test, the average depression before and after the intervention in the intervention group was significantly different $(p<0.001)$. However, there was no significant difference in the control group.

Table 4 presents the effect size of pain and depression calculated after intervention in the intervention and control groups.

Table 4. Effect size of post-intervention difference between intervention and control groups.

\begin{tabular}{|c|c|c|c|}
\hline Effect size & Mean \pm SD & Group & \\
\hline \multirow{2}{*}{-3.12} & $32 / 7 \pm 6 / 58$ & Intervention & \multirow{2}{*}{ Pain } \\
\hline & $53 / 29 \pm 13 / 25$ & Control & \\
\hline \multirow{2}{*}{-1.13} & $30 / 09 \pm 10 / 46$ & Intervention & \multirow{2}{*}{ Depression } \\
\hline & $18 / 19 \pm 9 / 31$ & Control & \\
\hline
\end{tabular}

\section{Discussion}

This study determined the effect of spiritual care on depression after coronary artery bypass surgery. The results showed that the mean depression score had a significant difference between the intervention and control groups after spiritual care $(p<0.001)$. This finding is consistent with the results of other researchers.

Nabolsi and Carson (2011) found that patients' faith and spiritual beliefs may facilitate and enhance patients' acceptance and coping with illness, strengthen their inner strength, hope, acceptance, and self-care, and would help them understand that life has meaning (Nabolsi and Carson 2011). 
Beckelman et al. studied people with heart disease between 2004-2005, and indicated that spiritual well-being is inversely associated with depression (Bekelman et al. 2007). Bussing demonstrated the role of spiritual beliefs in reducing depression, pain and social isolation, and increasing life satisfaction (Büssing et al. 2005). Hosseini et al.'s findings showed that spiritual care could reduce anxiety in Shia Muslim patients undergoing CABG (Hosseini et al. 2013). Spiritual activities such as non-organic and rehabilitation intervention can lead to improved self-care in patients (Falahi-Khoshknab and Ghazanfari 2007). Spirituality is a part of nursing care, and it can enhance patients' satisfaction effectively (Fatemi et al. 2016).

The results showed that patients' depression decreased after spiritual care among patients who underwent CABG. Spiritual care should be part of nursing holistic care and appropriate to the needs of individual patients. Spiritual beliefs help to focus perceptions considering the individual and their relationship with the world. Such belief gives them an inner strength that will blend very closely with their physical and mental health.

Our findings indicated that a spiritual/religious intervention had a positive effect on reducing patients' postoperative depression in Shia Muslim patients. Despite these strengths, this study has several limitations. These limitations were that the intervention was limited in use to a Shia Muslim population (using words associated with the Shia faith, and sentences based on Islamic Supplication $\mathrm{Zikr}$ ), and there was no measure of the impact of social or environmental factors.

The results show that the potential effect of spiritual care is to reduce postoperative depression of patients after CABG surgery. For nursing professionals, it is necessary to accommodate and consider the spiritual needs of patients. Overall, nurses' attention to patients' spiritual needs and providing this care may be useful in minimizing patients' depression. It is necessary to undertake similar studies in other religious populations.

\section{Limitations}

The limitations of this study were that the intervention was limited in use to a Shia Muslim population (using words associated with the Shia faith, and sentences based on Islamic Supplication Zikr), and there was no measure of the impact of social or environmental factors.

\section{Conclusions}

This study identified the role of spiritual care as a potentially useful and culturally appropriate intervention to decrease depression following CABG in Shia Muslim patients, and suggested that it may have utility in other populations and care settings.

Author Contributions: Conceptualization, M.H. and F.T.; Methodology, M.R., A.R.; Software, F.T. and M.R.; Validation, M.R., M.H. and M.F.K.; Formal Analysis, A.R.; Investigation, F.T., M.H.; Writing-Original Draft Preparation, M.H. and F.T.; Writing-Review \& Editing, Patricia Mary Davidson; Visualization, M.H.; Supervision, M.H.; Project Administration, M.F.K.; Funding Acquisition, M.H.

Acknowledgments: This study was part of a master's of nursing thesis conducted at the University of Social Welfare and Rehabilitation Sciences. The authors appreciate the cooperation and contribution of all patients and who don't meet the criteria for authorship, such as Miss Shima Shirozhan's who provided technical help and writing assistance.

Conflicts of Interest: The authors declare no conflict of interest.

\section{References}

Adib-Hajbaghery, Mohsen, and Zahra Saeadnejad. 2016. Barriers to Provide Patients Admitted to Hospitals in Kashan with Spiritual Care: Nurses' Viewpoints. Medical Ethics Journal 10: 49-59. [CrossRef]

Bekelman, Davia B., Sydney M. Dy, Diane M. Becker, Ilan S. Wittstein, Danetta E. Hendricks, Traci E. Yamashita, and Sheldon H. Gottlieb. 2007. Spiritual well-being and depression in patients with heart failure. Journal of General Internal Medicine 22: 470-77. [CrossRef] [PubMed] 
Braxton, Nikia D., Delia L. Lang, Jessica M. Sales, Gina M. Wingood, and Ralph J. DiClemente. 2007. The role of spirituality in sustaining the psychological well-being of HIV-positive black women. Women $\mathcal{E}$ Health 46: 113-29.

Büssing, Arndt, Thomas Ostermann, and Peter F. Matthiessen. 2005. Role of religion and spirituality in medical patients: Confirmatory results with the SpREUK questionnaire. Health and Quality of Life Outcomes 3: 10. [CrossRef] [PubMed]

Carney, Robert M., and Kenneth E. Freedland. 2008. Depression in patients with coronary heart disease. The American Journal of Medicine 121: S20-27. [CrossRef] [PubMed]

Doering, Lynn V., Debra K. Moser, Walter Lemankiewicz, Cristina Luper, and Steven Khan. 2005. Depression, healing, and recovery from coronary artery bypass surgery. American Journal of Critical Care 14: 316-24. [PubMed]

Duits, Annelien, Hugo Duivenvoorden, Saskia Boeke, Bas Mochtar, Jan Passchier, and Ruud Erdman. 2002. Psychological and somatic factors in patients undergoing coronary artery bypass graft surgery: Towards building a psychological framework. Psychology and Health 17: 159-71. [CrossRef]

Eisenberg, Mark J., Kristian B. Filion, Arik Azoulay, Anya C. Brox, Seema Haider, and Louise Pilote. 2005. Outcomes and cost of coronary artery bypass graft surgery in the United States and Canada. Archives of Internal Medicine 165: 1506-13. [CrossRef] [PubMed]

Falahi-Khoshknab, Masoud, and Nahid Ghazanfari. 2007. The Effect of Group Recreational Activities on the Self Care Skills of Schizophrenic Patients. IJNR 2: 25-30.

Fatemi, Mir Massoud, Robab Nazari, Mahboubeh Safavi, Mohammad Kazem Naini, and Mohammad Taghi Savadpour. 2016. The Relationships between nurses' spirituality and PATIENTS'SATISFACTION in the Hospitals of Ardabil University of Medical Science. Medical Ethics Journal 5: 141-59.

Freedland, Kenneth E., Judith A. Skala, Robert M. Carney, Eugene H. Rubin, Patrick Lustman, Victor G. Dávila-Román, Brain C. Steinmeyer, and Charles W Hogue. 2009. Treatment of depression after coronary artery bypass surgery: A randomized controlled trial. Archives of General Psychiatry 66: 387-96. [CrossRef] [PubMed]

Gallagher, Robyn, and Sharon McKinley. 2009. Anxiety, depression and perceived control in patients having coronary artery bypass grafts. Journal of Advanced Nursing 65: 2386-96. [CrossRef] [PubMed]

Hanifi, Nasrin, Nasrin Bahraminejad, Tayebeh Mirzaee, Fazilillah Ahmadi, Mohammad Khani, and Leila Taran. 2012. The effect of orientation program on stress, anxiety and depression of patients undergoing coronary angiography. IJNR 7: 1-8.

Holzapfel, Nicole, Bernd Löwe, Beate Wild, Dieter Schellberg, Christian Zugck, Andrew Remppis, Hugo A. Katus, Markus Haass, Bernhard Rauch, Jana Jünger, and et al. 2009. Self-care and depression in patients with chronic heart failure. Heart E Lung: The Journal of Acute and Critical Care 38: 392-97. [PubMed]

Hosseini, Mohammadali, Patricia M. Davidson, Masoud Fallahi Khoshknab, and Anna Green. 2013. Spiritual and religious interventions in health care: An integrative review. Iranian Rehabilitation Journal 11: 87-93.

Jamshidi, Nhid, Abas Abaszade, and Majid Najafi-Kaliani. 2012. Stress, anxiety and depression of patients before coronary angiography. Zahedan Journal of Research in Medical Sciences 13: 29.

Karimollahi, Mansoureh, Heidar ali Abedi, and Alireza Yousefi. 2008. Antecedents of spiritual distress experienced by Iranian Muslim patients. Research Journal of Biological Science 3: 1815-46.

Koenig, Harold G. 2007. Religion and remission of depression in medical inpatients with heart failure/pulmonary disease. The Journal of Nervous and Mental Disease 195: 389-95. [PubMed]

McCoubrie, Rachel C., and Andrew N. Davies. 2006. Is there a correlation between spirituality and anxiety and depression in patients with advanced cancer? Supportive Care in Cancer 14: 379. [CrossRef] [PubMed]

Melhem, Ghaith Ahmad Bani, Ruqayya S. Zeilani, Ossama Abed Zaqqout, Ashraf Ismail Aljwad, Mohammed Qasim Shawagfeh, and Maysoon Abd Al-Rahim. 2016. Nurses' perceptions of spirituality and spiritual care giving: A comparison study among all health care sectors in Jordan. Indian Journal of Palliative Care 22: 42-49. [CrossRef] [PubMed]

Nabolsi, Manar M., and Alexander M. Carson. 2011. Spirituality, illness and personal responsibility: The experience of Jordanian Muslim men with coronary artery disease. Scandinavian Journal of Caring Sciences 25: 716-24. [CrossRef] [PubMed] 
Oxman, Thomas E., Daniel H. Freeman, and Eric D. Manheimer. 1995. Lack of social participation or religious strength and comfort as risk factors for death after cardiac surgery in the elderly. Psychosomatic Medicine 57: 5-15. [CrossRef] [PubMed]

Rafanelli, Chiara, Renzo Roncuzzi, and Yuri Milaneschi. 2006. Minor depression as a cardiac risk factor after coronary artery bypass surgery. Psychosomatics 47: 289-95. [CrossRef] [PubMed]

Ravven, Simha, Caroline Bader, Armin Azar, and James L. Rudolph. 2013. Depressive symptoms after CABG surgery: A meta-analysis. Harvard Review of Psychiatry 21: 59-69. [CrossRef] [PubMed]

Rippentrop, A. Elizabeth, Elizabeth M. Altmaier, Joseph J. Chen, Ernest M. Found, and Valerie J. Keffala. 2005. The relationship between religion/spirituality and physical health, mental health, and pain in a chronic pain population. Pain 116: 311-21. [CrossRef] [PubMed]

Ross, Linda. 2006. Spiritual care in nursing: An overview of the research to date. Journal of Clinical Nursing 15: 852-62. [CrossRef] [PubMed]

Rutledge, Thomas, Viola Vaccarino, B. Delia Johnson, Vera Bittner, Marian B. Olson, Sarah Elizabeth Linke, Carol E. Cornell, Wafia Eteiba, David Sheps, Jennifer Francis, and et al. 2009. Depression and cardiovascular health care costs among women with suspected myocardial ischemia: Prospective results from the WISE (Women's Ischemia Syndrome Evaluation) Study. Journal of the American College of Cardiology 53: 176-83. [CrossRef] [PubMed]

Sahebi, Ali, Mohammad Javad Asghari, and Razie Sadat Salari. 2005. Validation of depression anxiety and stress scale (DASS-21) for an Iranian population. Iranian Psychologists. Available online: https:/ / www.scienceopen. com/document?vid=7528f000-2e97-4811-8ff0-028faa5b3d8c (accessed on 14 May 2018).

Smith, Timothy B., Jeremy Bartz, and P. Scott Richards. 2007. Outcomes of religious and spiritual adaptations to psychotherapy: A meta-analytic review. Psychotherapy Research 17: 643-55. [CrossRef]

Stafford, Lesley, Michael Berk, Prasuna Reddy, and Henry J. Jackson. 2007. Comorbid depression and health-related quality of life in patients with coronary artery disease. Journal of Psychosomatic Research 62: 401-10. [CrossRef] [PubMed]

Vural, Mutlu, Mehmet Acer, and Berfu Akbaš. 2008. The scores of Hamilton depression, anxiety, and panic agoraphobia rating scales in patients with acute coronary syndrome. Anatolian Journal of Cardiology/Anadolu Kardiyoloji Dergisi 8: 43-47. [PubMed]

Whelan-Gales, Mary Ann, Mary T. Quinn Griffin, Judith Maloni, and Joyce J. Fitzpatrick. 2009. Spiritual well-being, spiritual practices, and depressive symptoms among elderly patients hospitalized with acute heart failure. Geriatric Nursing 30: 312-17. [CrossRef] [PubMed]

(C) 2018 by the authors. Licensee MDPI, Basel, Switzerland. This article is an open access article distributed under the terms and conditions of the Creative Commons Attribution (CC BY) license (http://creativecommons.org/licenses/by/4.0/). 